Supporting Information:

\title{
Computational and Experimental Evaluation of Peroxide Oxidants for Amine-Peroxide Redox Polymerization
}

Charles B. Musgrave III ${ }^{1,6, \|}$, Kangmin $\mathrm{Kim}^{2}{ }^{2}$, Nicholas R. Singstock, ${ }^{1}$ Austyn M. Salazar ${ }^{1,3}$, Jeffrey W. Stansbury ${ }^{1,3}$, Charles B. Musgrave $e^{* 1,2,4,5}$

${ }^{1}$ University of Colorado Boulder, Department of Chemical and Biological Engineering, Boulder, CO, 80309, United States

${ }^{2}$ University of Colorado Boulder, Department of Chemistry, Boulder, CO, 80309, United States

${ }^{3}$ University of Colorado Denver, School of Dental Medicine, Craniofacial Biology, Aurora, CO, 80045, United States

${ }^{4}$ Materials Science and Engineering Program, University of Colorado, Boulder, CO, 80309, United States

${ }^{5}$ National Renewable Energy Laboratory, Golden, CO 80401, United States

${ }^{6}$ Materials and Process Simulation Center, California Institute of Technology, Pasadena, CA 91125, United States

"These authors contributed equally to this work

${ }^{*}$ Corresponding Author (charles.musgrave@colorado.edu)

\section{Table of Contents}

S1: Methods . . . . . . . . . . . . . . . . . . . . . . . Pg. S2

S2: Phthaloyl Peroxide . . . . . . . . . . . . . . . . . . . . Pg. S3

S3: Polymerization Profiles . . . . . . . . . . . . . . . . . . Pg. S3

S4: NMR Plots . . . . . . . . . . . . . . . . . . . . . . . . . Pg. S9

S5: Directing Writing System . . . . . . . . . . . . . . . . . . . Pg. S11

S6: References . . . . . . . . . . . . . . . . . . . . . Pg. S11 


\section{S1. Methods}

\section{S1.1. Computational Methods.}

All Density Functional Theory calculations were computed via the GAUSSIAN 16 Revision A.03 software package ${ }^{1}$ using Truhlar's MN15 density functional ${ }^{2}$ and the $6-31+G(d, p)$ basis set. ${ }^{3}$ The Universal solvation model based on electron density (SMD) was used to treat solvent effects. ${ }^{4}$ We utilized the MN15 functional because it out-performed 13 other popular functionals when compared to the chemically accurate but computationally expensive $\operatorname{CBS}-\mathrm{QB} 3^{5}$ and $\operatorname{CCSD}(\mathrm{T})^{6}$ methods. We previously found $\mathrm{MN} 15$ to have a $1.4 \mathrm{kcal} / \mathrm{mol} \mathrm{RMS}$ error for reaction intermediates and transition states relative to the energies from CBSQB3. MN15's accuracy can be attributed to its ability to describe multi-reference configurations and noncovalent interactions. These characteristics of MN15 are imperative for our chemistry because some of our intermediates and transition states were found to exhibit multi-reference character. Phonons were calculated to verify reaction intermediates and transition states, as well as to compute thermochemical properties at $298 \mathrm{~K}$ including entropies, enthalpies, and free energies. For the SMD solvation model, we sought for parameters that would describe (meth)acrylate monomers. Because ethyl acetate (EtOAc) is structurally similar to (meth)acrylate, we chose solvent parameters that describe EtOAc. EtOAc's dielectric constant is $\sim 6$, which is well within (meth)acrylate's dielectric range of 2.5 to 11 . $^{7}$

\section{S1.2. Experimental Methods}

We measured the progress of polymerization by monitoring the $\mathrm{C}=\mathrm{C}$ stretching absorption band at $1637 \mathrm{~cm}^{-1}$ for 20 mins in OMNIC software with an FT-IR spectrophotometer (Nicolet Magna-IR Series II, Thermo Scientific, West Palm Beach, FL). DEGEEA monoacrylate was chosen to reduce a confounding factor of auto acceleration. The spectrophotometer was equipped with an MCT/A detector, and parameters on the FT-IR were set to 2 scans, a resolution of 16 , an optical gain of 1 , an optical velocity of 1.8988 , and an optical aperture of 15 . The polymerization was initiated with two separate batches of resin with $3 \mathrm{~mol} \%$ of DMA reductant and various peroxides. We first deposited $15 \mu 1$ of peroxide resin on a horizontal $\mathrm{NaCl}$ salt plate, to which another $15 \mu \mathrm{l}$ of DMA resin was added. This solution was then mixed with micropipette tips. Another $\mathrm{NaCl}$ salt plate was then placed on top of the mixture, after which data acquisition began immediately. We observed a clear baseline of zero conversion during an induction period preceding each polymerization for every sample. The concentrations of the oxidant and reductant were chosen to accommodate $\sim 60$ seconds of sample preparation through an induction time and to capture the entire polymerization process. 


\section{S2. Phthaloyl peroxide}

We next investigated whether PhthPO might be viable as the peroxide for APRP when paired with a nucleophilic amine that may drive it to undergo the desired inner-sphere ET. A more nucleophilic amine has a greater driving force for attack on an electrophilic site, meaning SN2 attack on an electrophilic oxygen should be more facile. We chose to examine 1-methylpyrrolidine (MePy) as the nucleophilic amine that might facilitate inner-sphere ET with PhthPO. We calculated rate constants for inner and outer sphere ET to afford the amine radical cation and peroxide radical anion products. We found the $\mathrm{S}_{\mathrm{N}} 2$ and HM barriers to be 3.8 and $24.2 \mathrm{kcal} / \mathrm{mol}$, corresponding to a respectable $k_{r}$ of $0.2 \mathrm{~s}^{-1}$ for the MePy-PhthPO pair. While this $k_{r}$ is considerably higher than that for the standard DMA amine we predict that the $k_{r}$ for outer-sphere ET also improves; We predict the MePy-PhthPO $k_{O S}$ to be $35.0 \mathrm{~s}^{-1}$, over two orders of magnitude higher than $k_{r}$. This prediction is confirmed by experiment. We again synthesized PhthPO, mixed it with MePy, and monitored the initiation behavior using FT-IR. Again, we observed negligible amount of polymerization, and the solution changed color to blue. We concluded that PhthPO favors outer-sphere ET regardless of the amine's nucleophilicity, rendering it incompetent as a peroxide to initiate APRP.

\section{S3: Polymerization Profiles}

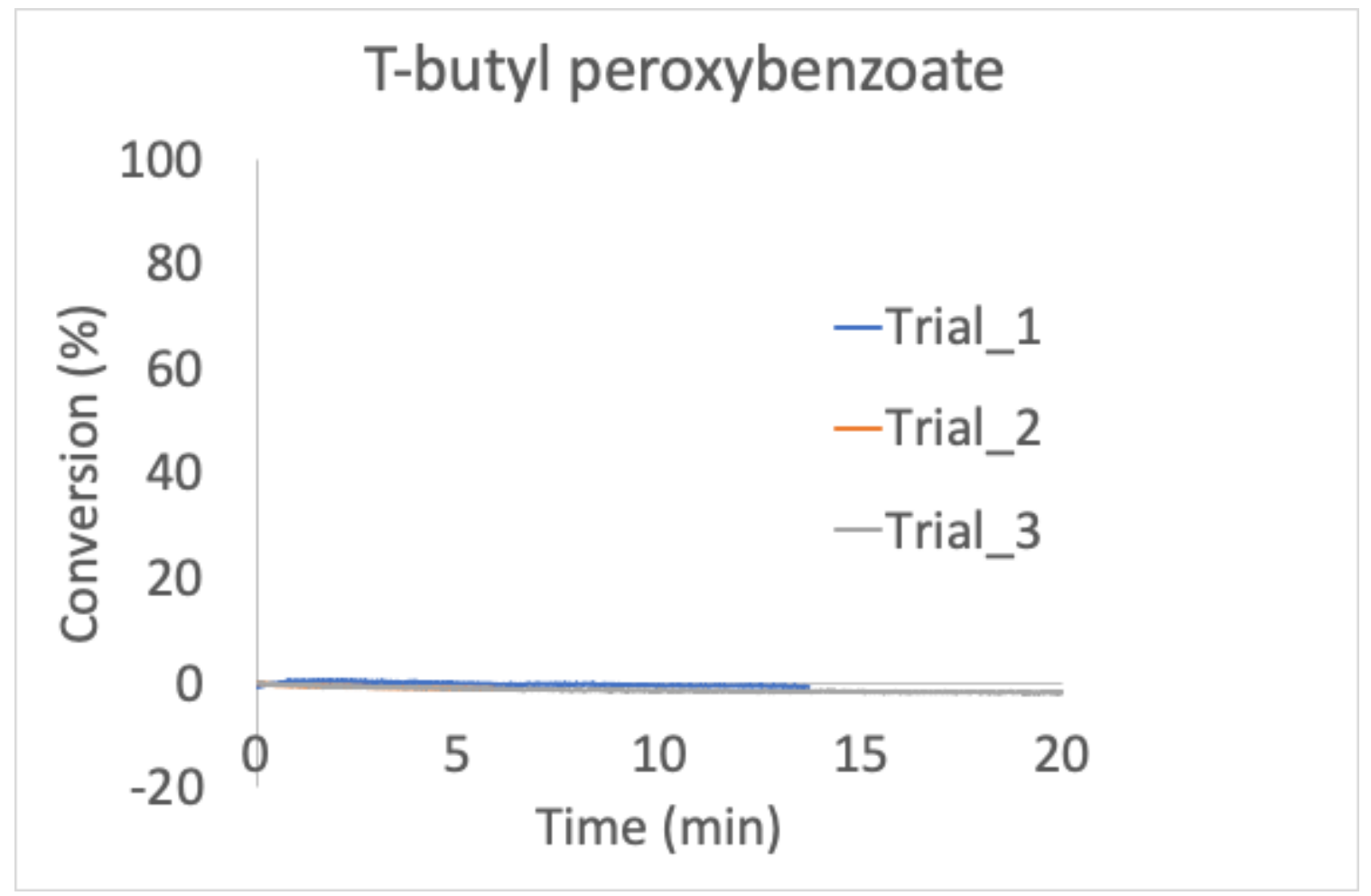

Figure S1. Polymerization profiles of t-butyl peroxybenzoate 


\section{Phthaloyl peroxide}

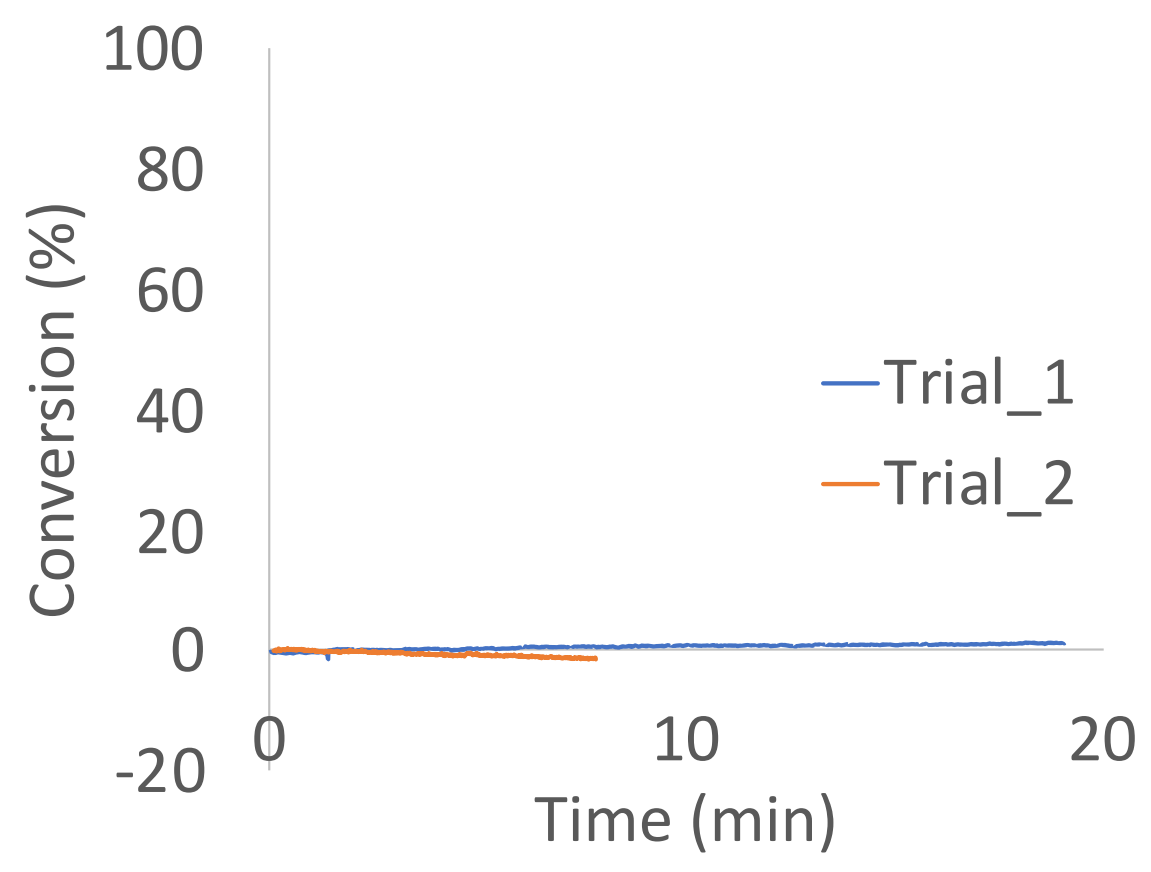

Figure S2. Polymerization profiles of phthaloyl peroxide.

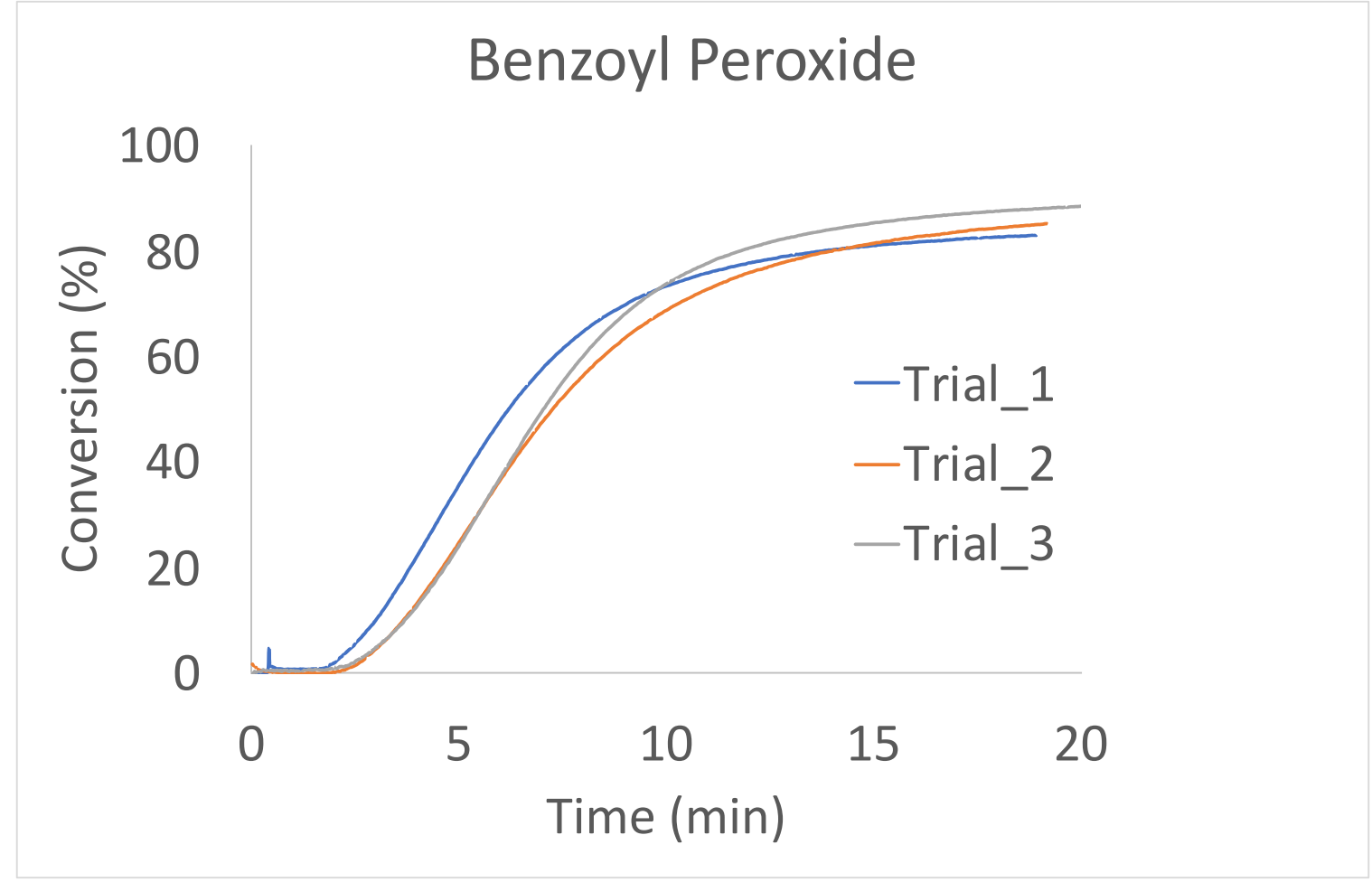

Figure S3. Polymerization profiles of benzoyl peroxide. 


\section{T-butyl peroxide}

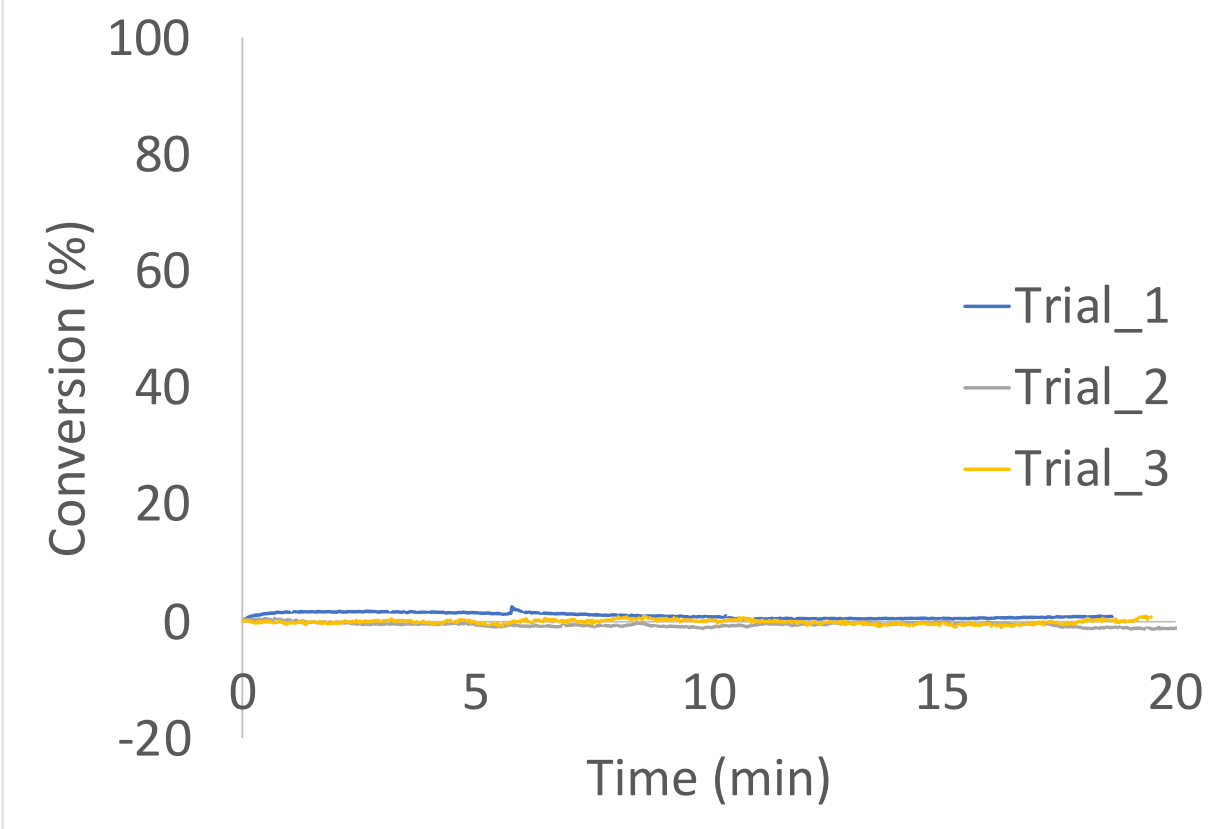

Figure S4. Polymerization profiles of t-butyl peroxide.

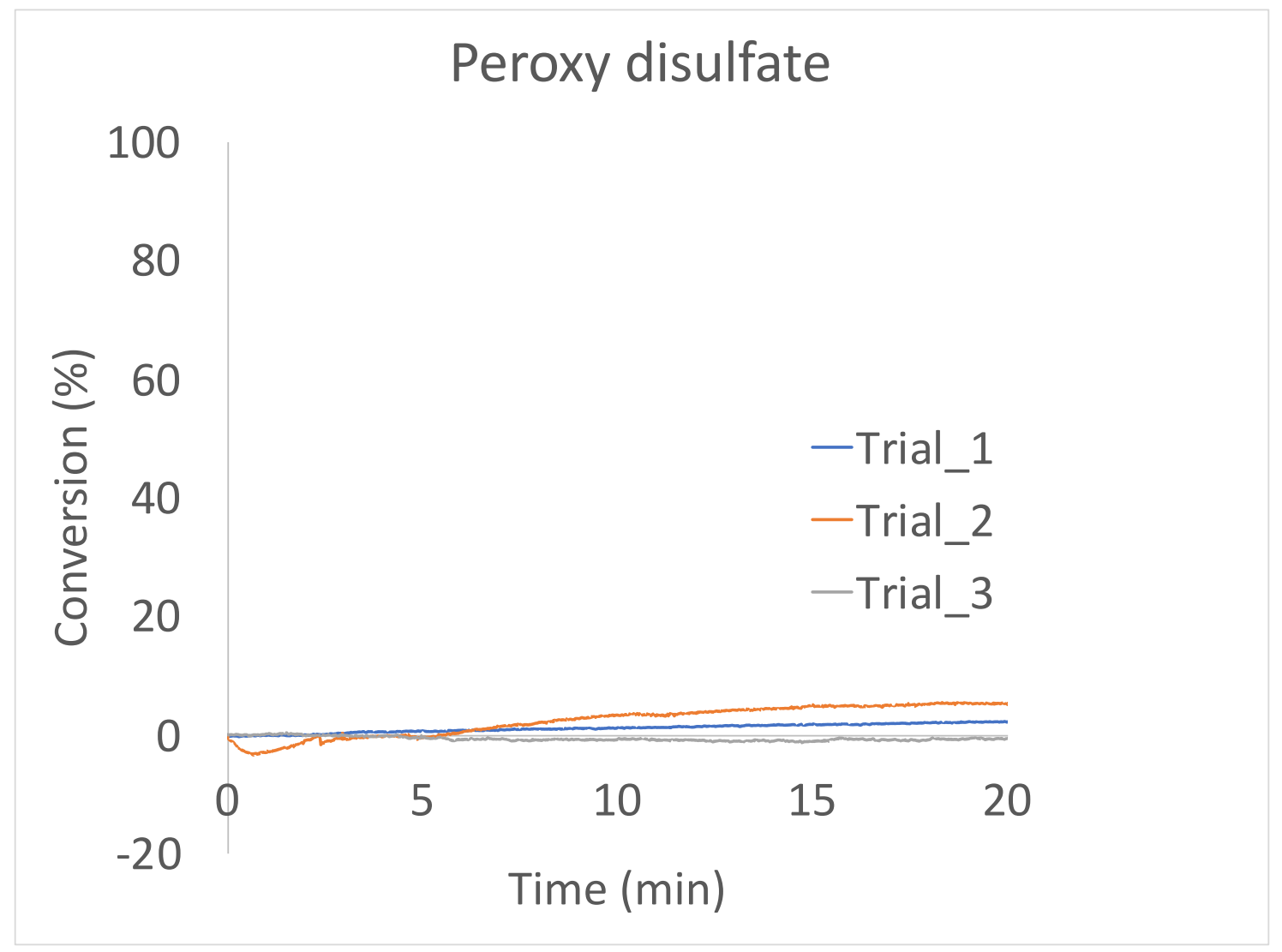

Figure S5. Polymerization profiles of peroxy disulfate. 


\section{Cumyl peroxide}

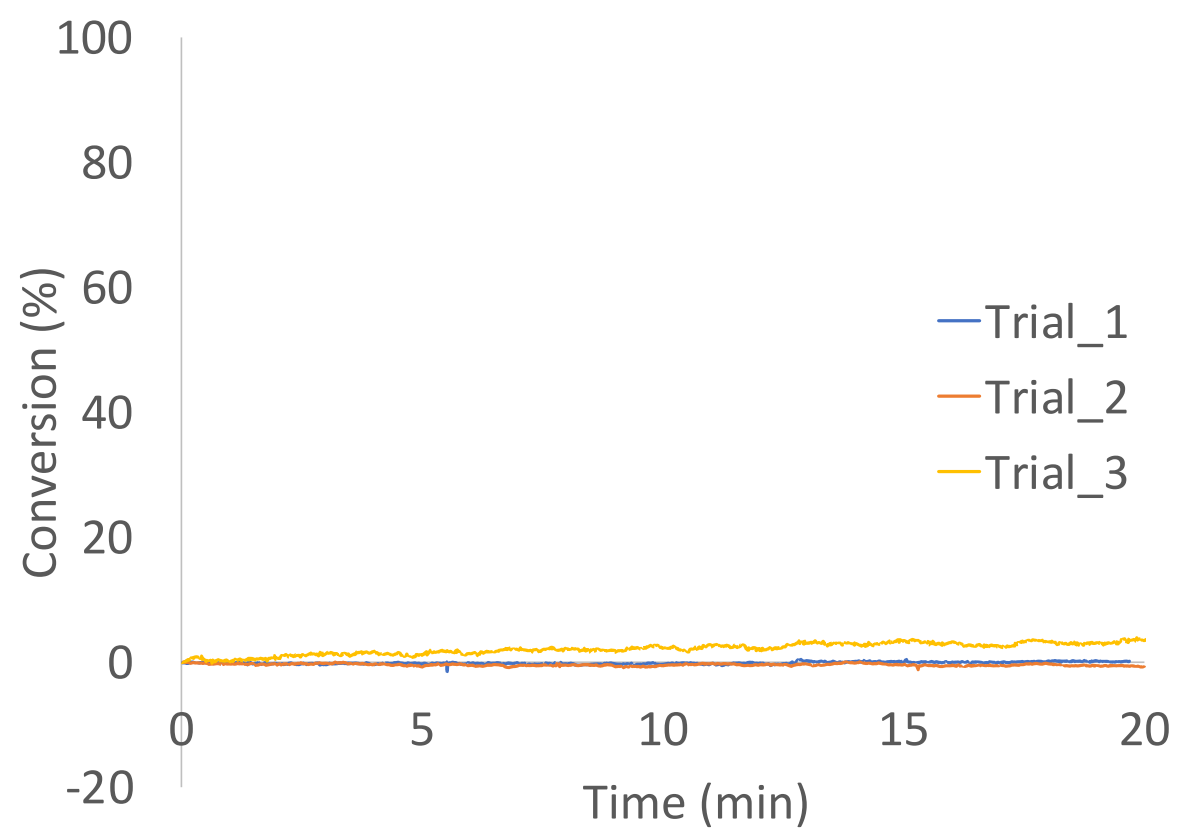

Figure S6. Polymerization profiles of cumyl peroxide.

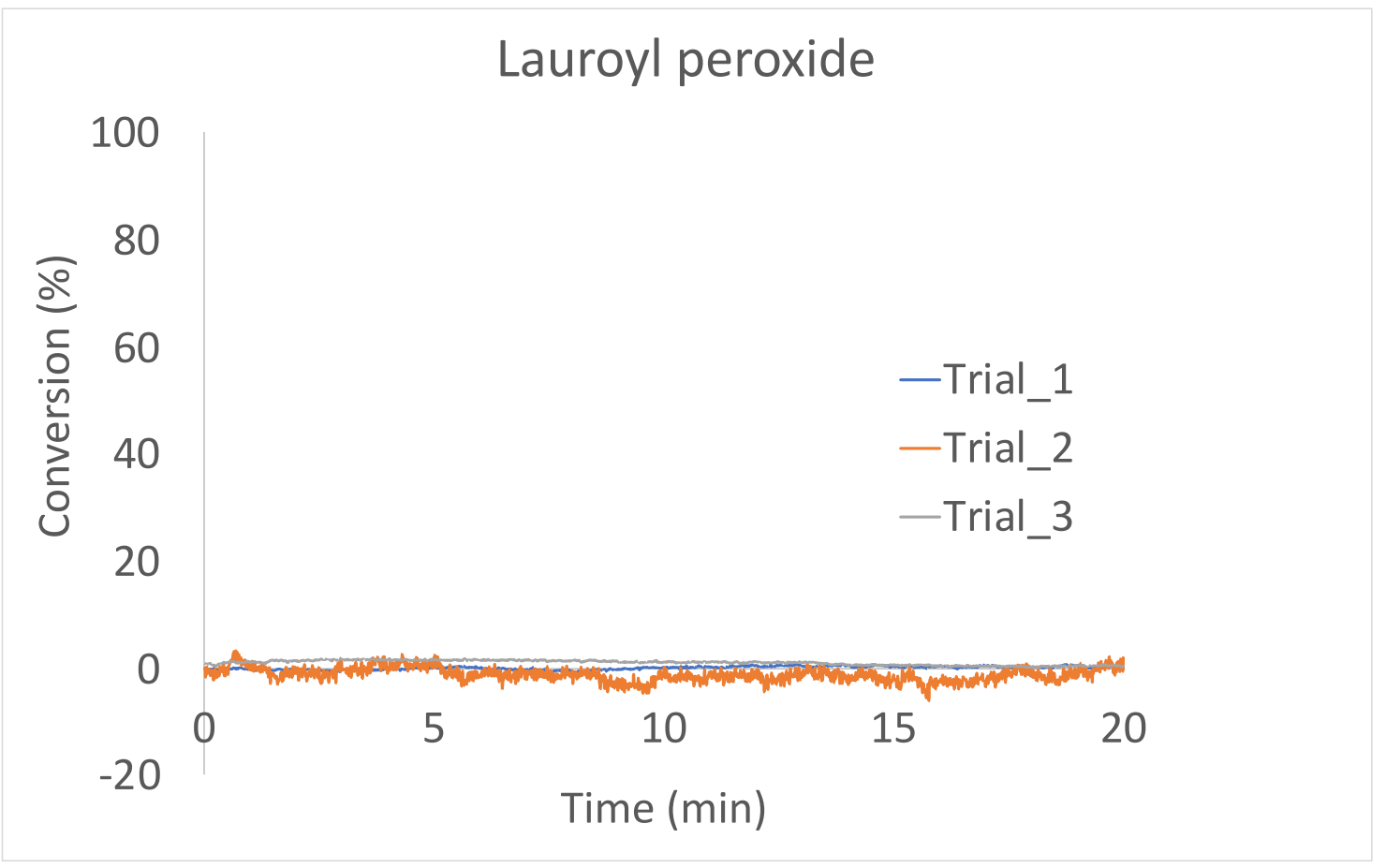

Figure S7. Polymerization profiles of lauroyl peroxide. 


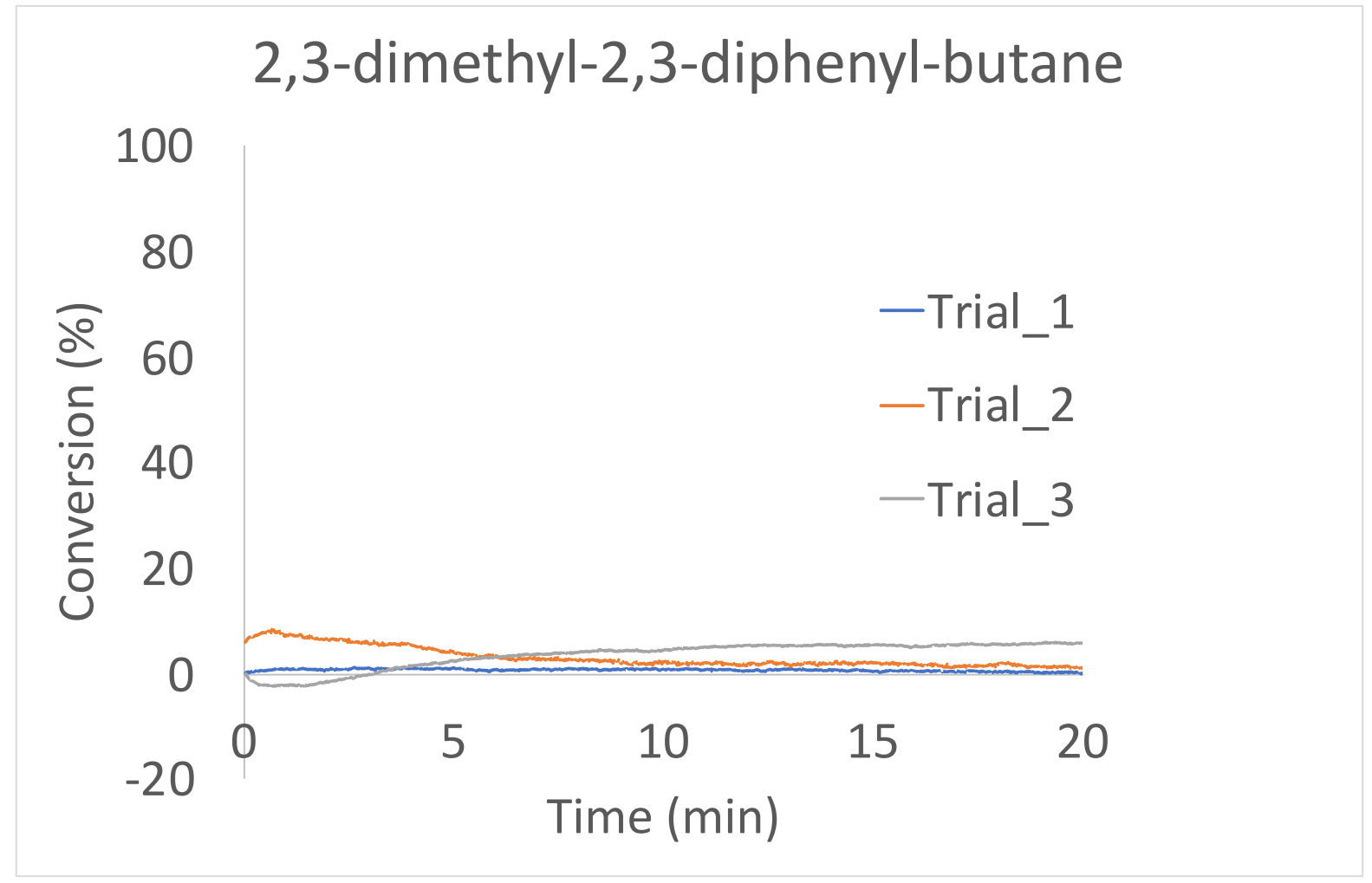

Figure S8. Polymerization profiles of 2,3-dimethyl-2,3-diphenyl-butane.

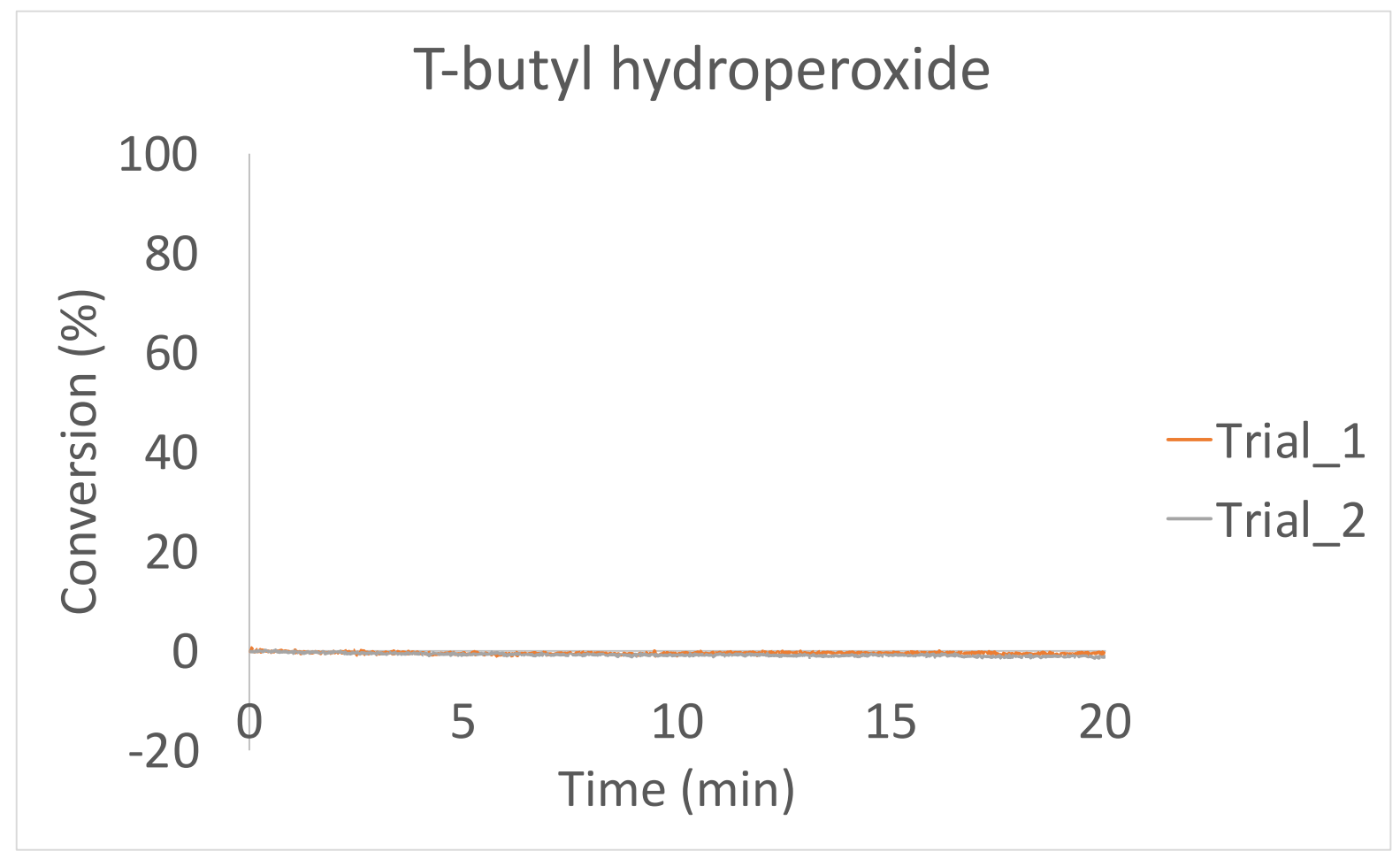

Figure S9. Polymerization profiles of t-butyl hydroperoxide. 


\section{Hydrogen peroxide}

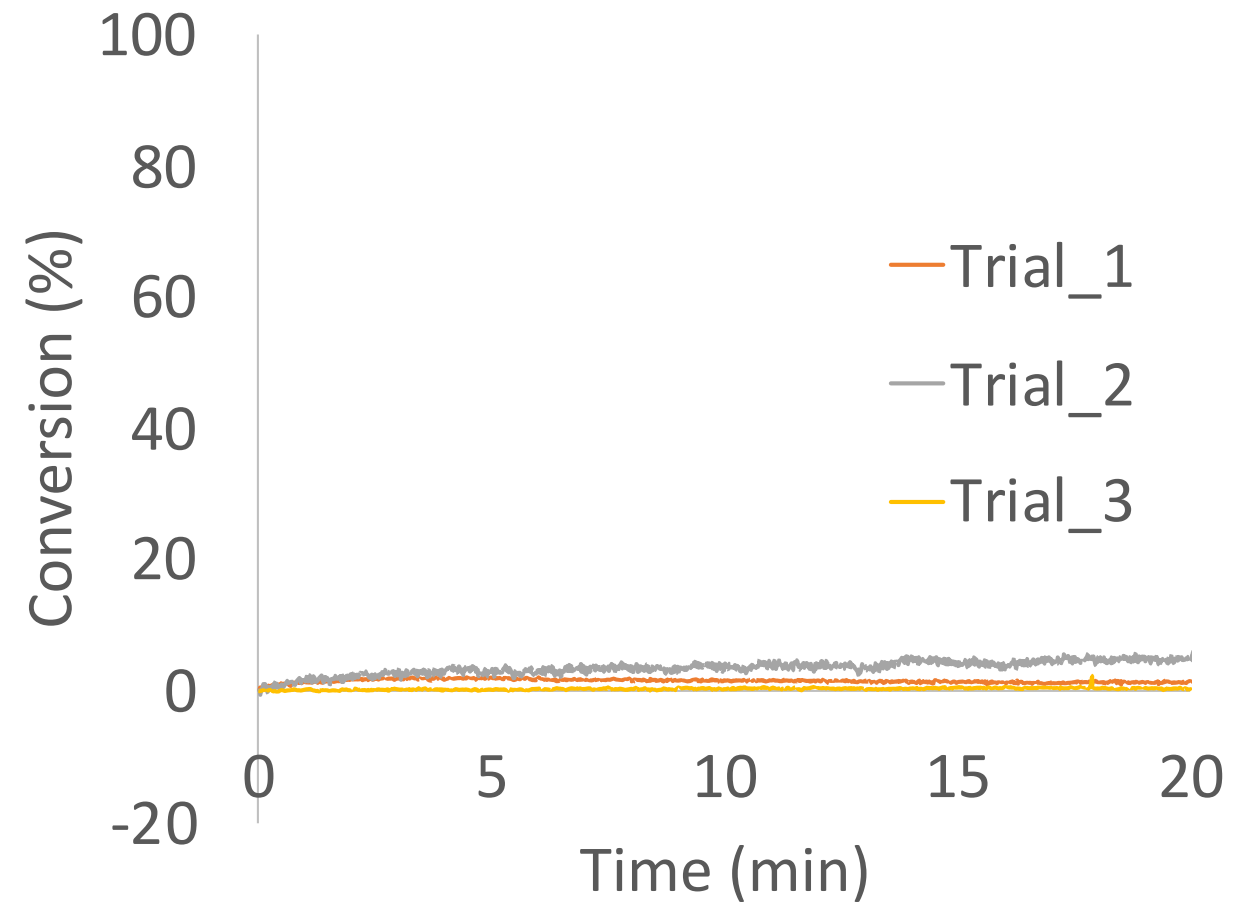

Figure S10. Polymerization profiles of hydrogen peroxide. 


\section{S4. NMR spectra}

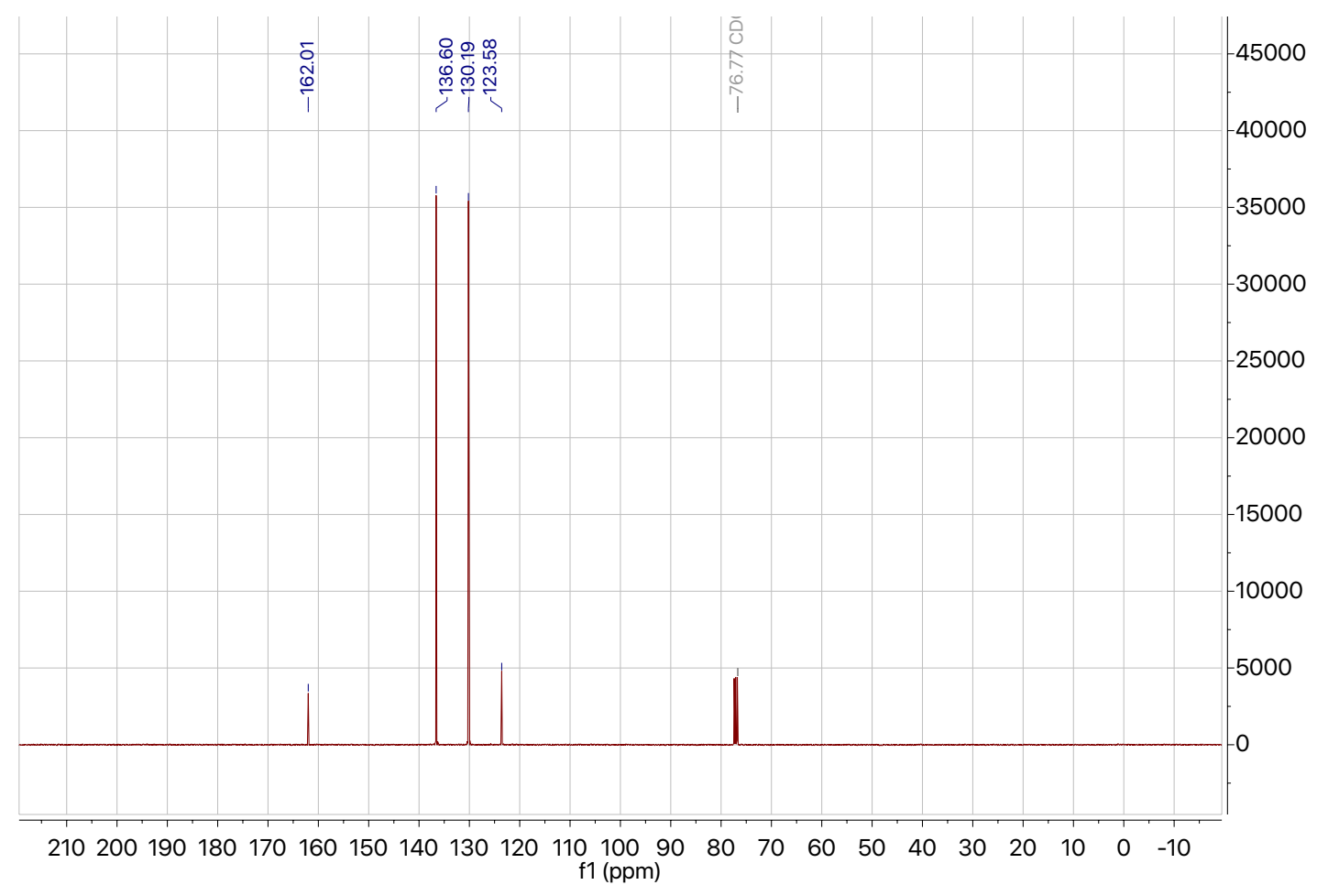

Figure S11. ${ }^{13} \mathrm{C}$-NMR of $\mathrm{N}$-(4-Methoxyphenyl)pyrrolidine.

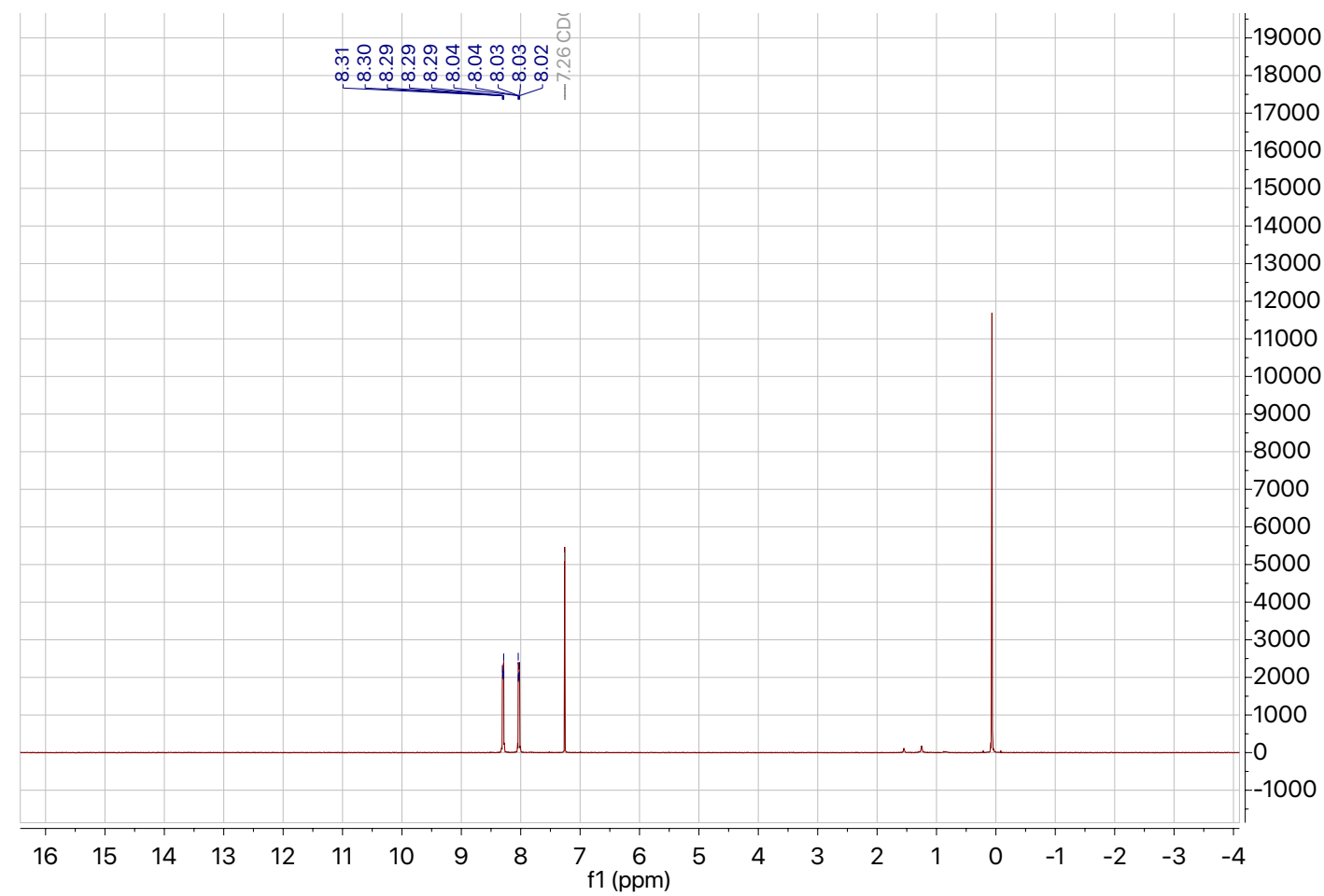

Figure S12. ${ }^{1} \mathrm{H}-\mathrm{NMR}$ of $\mathrm{N}$-(4-Methoxyphenyl)pyrrolidine. 


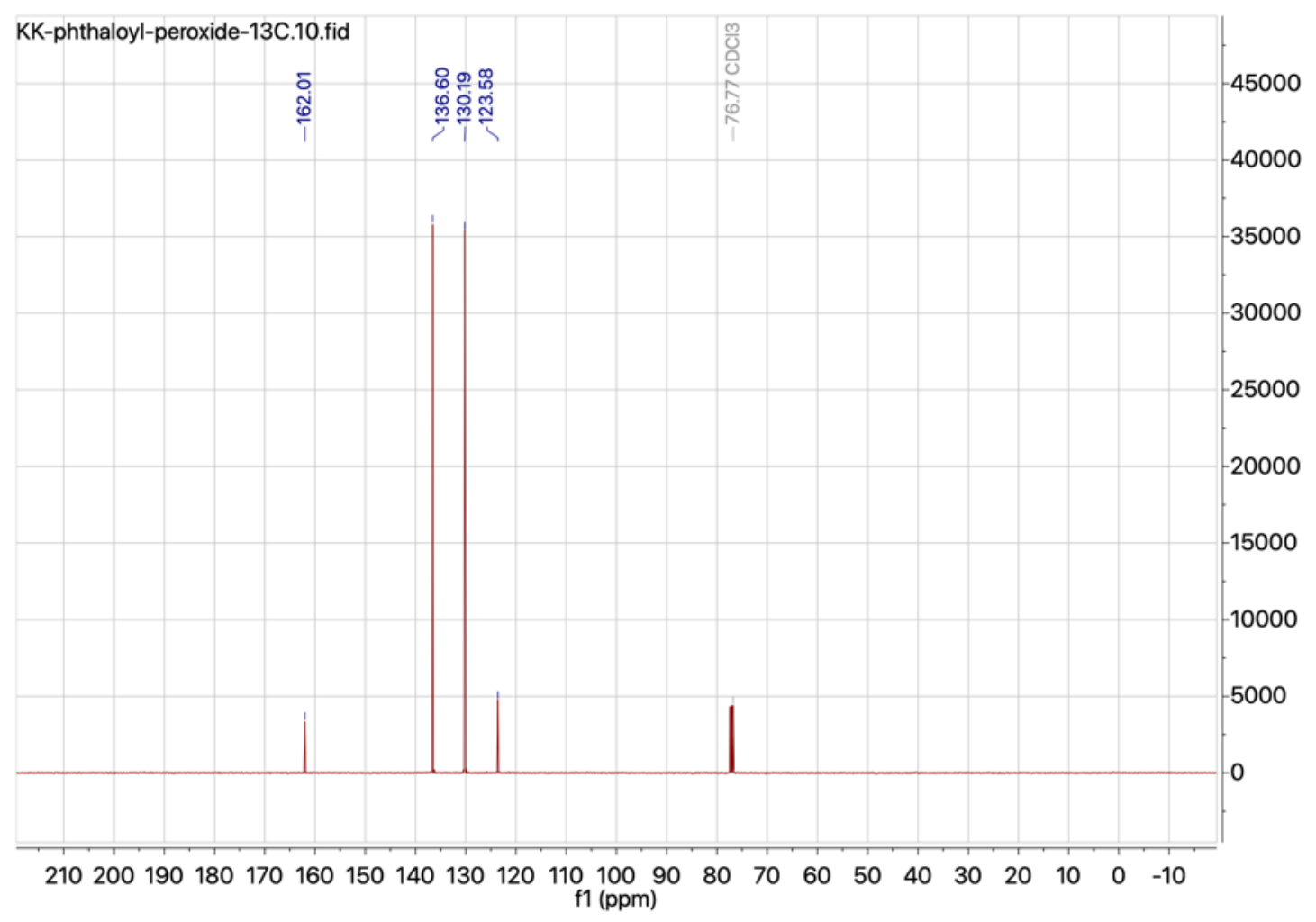

Figure S13. . ${ }^{13} \mathrm{C}-\mathrm{NMR}$ of phthaloyl peroxide.

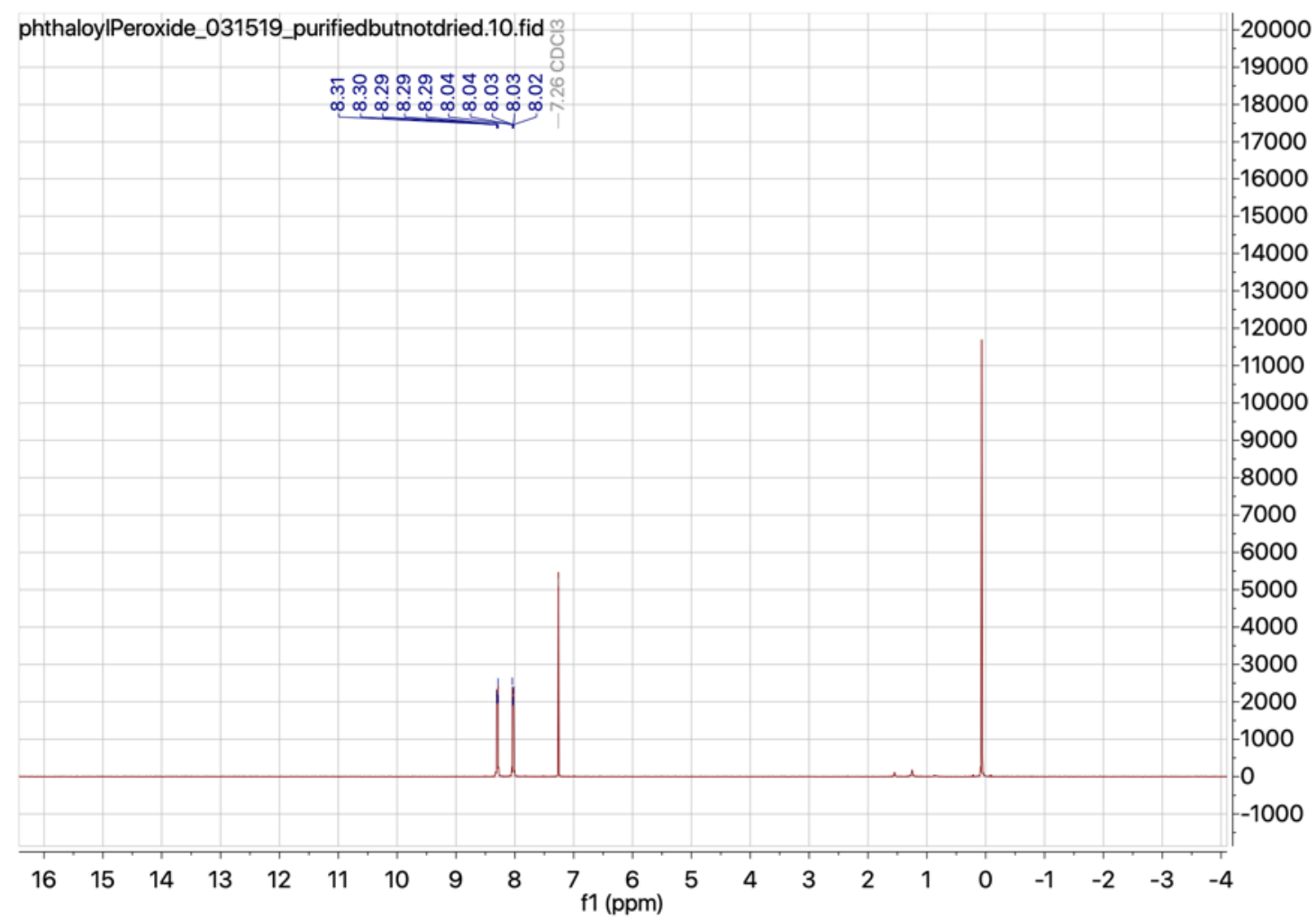

Figure S14. ${ }^{1} \mathrm{H}-\mathrm{NMR}$ of phthaloyl peroxide. 


\section{S5. APRP Direct Writing System:}

The 3D printer was built with a wooden frame, four stepper motors recycled from CD ROM components, and two $12 \mathrm{~V} \mathrm{DC}$ peristaltic pumps. $3 \mathrm{~mm}$ ID $\times 5 \mathrm{~mm}$ OD silicone tubing was used to flow the resins. A Raspberry Pi 3 model B+ was used as the controller for the printer. A4988 stepper motor controllers and 16 pin L293D drivers were used to control the stepper motors and pumps, respectively. Python scripts were developed to operate the Raspberry Pi and control the printing process.

A major limitation to our specific printer is that the pumps were not consistent enough to deliver a constant flow rate, and thus a consistent printed thickness. The inconsistency in the flow rates also resulted in inconsistent ratios of amine and peroxide resin in the mixing nozzle, which slowed curing times and further reduced resolution. It is likely that a more sophisticated printer could overcome both of these challenges and print with much finer resolution. Other major challenges to developing this technology further include optimizing curing times and material properties with different resin systems and fillers and transitioning between different resin systems in a single print to obtain variable material properties. 


\section{S6. References}

1. Frisch MJ, Trucks GW, Schlegel HB., et al. Gaussian 16. 2016.

2. Yu HS, He X, Li SL, Truhlar DG. MN15: A Kohn-Sham global-hybrid exchange-correlation density functional with broad accuracy for multi-reference and single-reference systems and noncovalent interactions. Chem Sci. 2016;7(8):5032-5051. doi:10.1039/C6SC00705H

3. Rassolov VA, Ratner MA, Pople JA, Redfern PC, Curtiss LA. 6-31G* basis set for third-row atoms. J Comput Chem. 2001;22(9):976-984. doi:10.1002/jcc.1058

4. Marenich A V., Cramer CJ, Truhlar DG. Universal solvation model based on solute electron density and on a continuum model of the solvent defined by the bulk dielectric constant and atomic surface tensions. $J$ Phys Chem B. 2009;113(18):6378-6396. doi:10.1021/jp810292n

5. Montgomery JA, Frisch MJ, Ochterski JW, Petersson GA. A complete basis set model chemistry. VII. Use of the minimum population localization method. J Chem Phys. 2000;112(15):6532-6542. doi:10.1063/1.481224

6. Purvis GD, Bartlett RJ. A full coupled-cluster singles and doubles model: The inclusion of disconnected triples. J Chem Phys. 1982;76(4):1910-1918. doi:10.1063/1.443164

7. Kim K, Singstock NR, Childress KK, et al. Rational Design of Efficient Amine Reductant Initiators for Amine-Peroxide Redox Polymerization. J Am Chem Soc. 2019;141(15):6279-6291. doi:10.1021/jacs.8b13679 